\title{
Good oral health is a basic right
}

The FDI World Dental Federation (FDI) has supported the need for good oral health on the World Health Organisation's (WHO) World Health Day, which focused on improving the health of mothers and children.

The theme for WHO's annual event, which took place in April, was to "Make Every Mother and Child Count".

In response to the global campaign, the FDI said women and children were among the most vulnerable populations in the world and often have higher levels of ill health and limited access to care.

"Good oral health is a basic human right and inseparable from general health and wellbeing. Only by taking a holistic approach to health promotion, by addressing risk factors that are shared by systemic and oral diseases, can we succeed in achieving improved levels of oral health for mothers and children", said FDI Executive Director Dr JT Barnard.

The Federation said that greater prominence needed to be given to equal provision of basic human rights, which included the right to good general and oral health.

The Federation said it supported action to

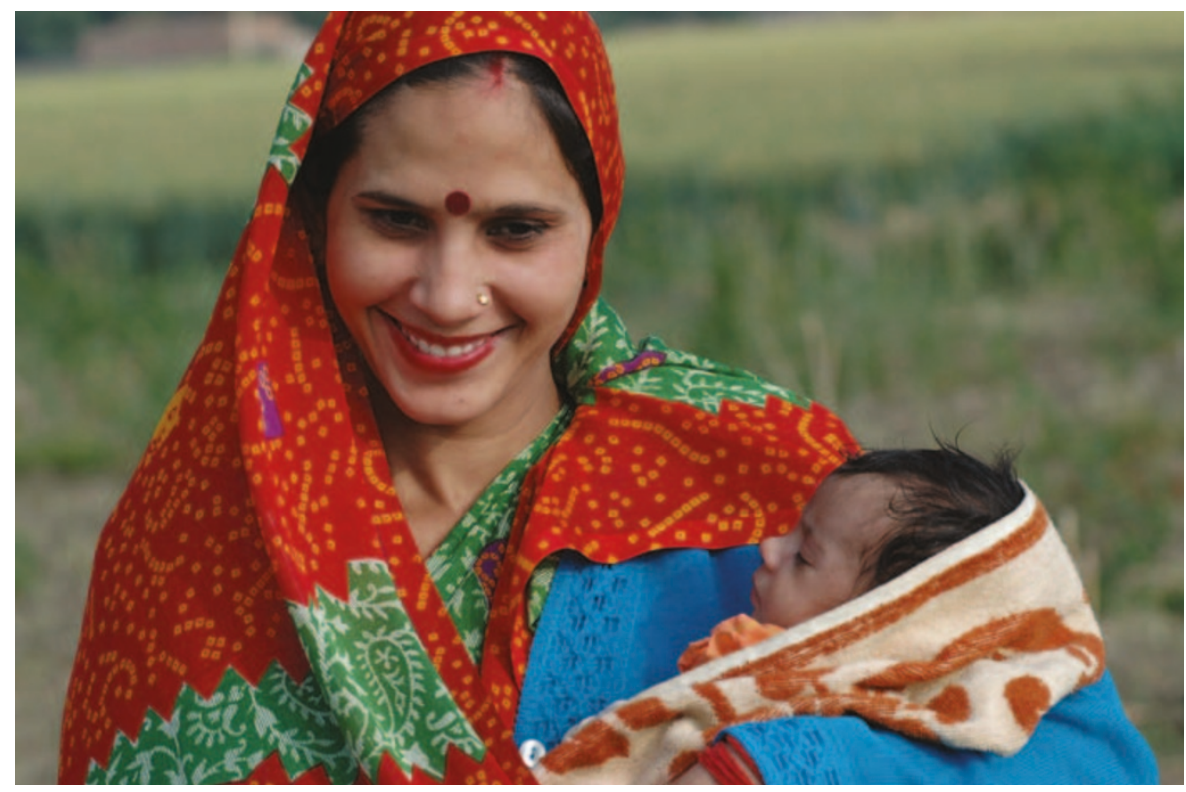

improve the health of mothers through asserting their basic human rights, including access to health care, education, employment opportunities and safe and healthy environments.

All health professionals, such as physicians, dentists, nurses or midwifes, must be aware of the serious impact of oral diseases on the health, nutrition and wellbeing of mothers and children, it said.

The promotion of oral health should be part of all health education programmes and appropriate oral health care services for children and their mothers should be available, said the Federation.

\section{Nurses win dental awards}

Three dental nurses have been presented with special awards for exceptional achievement at the recent Milton Keynes PCT's oral healthcare awards.

Allanna Davis, Sarah Pepper and Lera Lashmar received their prizes from deputy chief dental officer Barry Cockcroft and regional director for postgraduate dental education Dr Helen Falcon, who handed out more than 40 awards and certificates at the ceremony.

Lisa Webb, the PCT's NVQ tutor coordinator said "the significance of the evening was to celebrate the achievement of dental nursing across Buckinghamshire and Oxfordshire".

NVQ level two oral healthcare support awards went to Jennifer O'Mahoney, Janet Holman, Bilgin Hassan, Lucy Willans, Cynthia Wort, Morgan Williams, Karen Hickey, Caroline Galuszka, Katie Jordan, and Terri Bostic. NVQ level three oral healthcare dental nursing awards

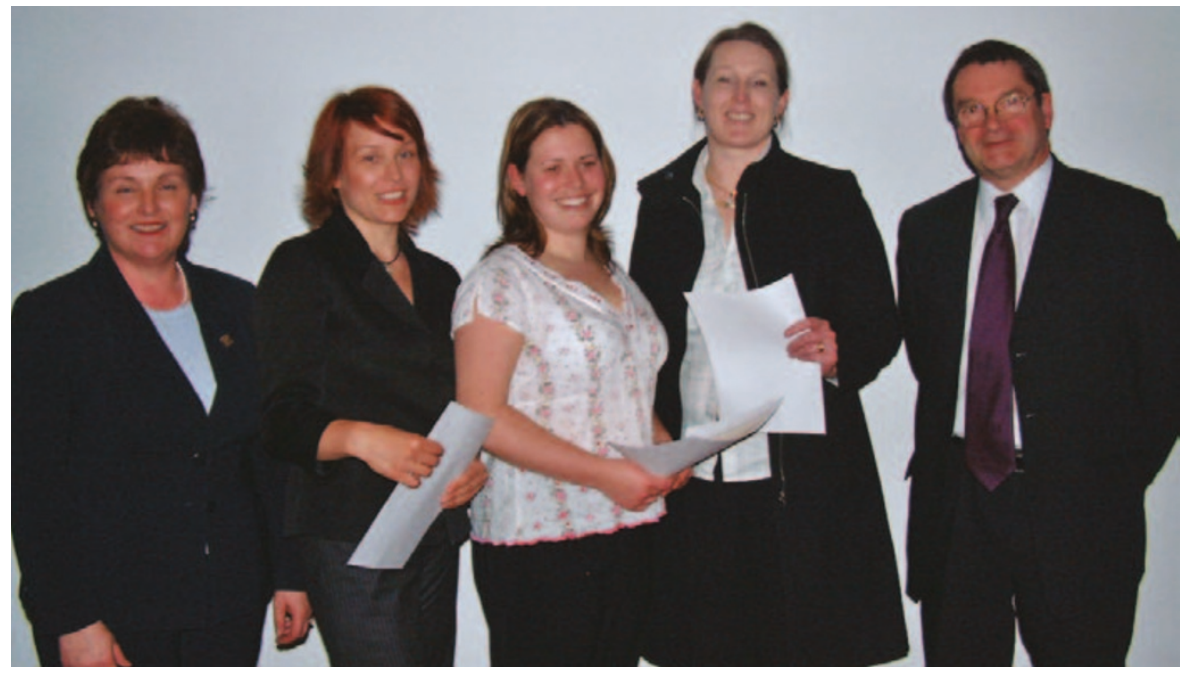

Left to right, Dr Helen Falcon with special award winners Lera Lashmar, Sarah Pepper and Allanna Davis and Dr Barry Cockcroft

were given to more than 30 recipients.

Assessor awards were given to Claire Moscrop, Janet Stewart, Jackie Owers, Letitia Dickinson, Joyce Krah, Jenni Jay, Amanda
Peel, Pearl Hirst, Elizabeth Pummary, Zoe Whitworth and Lisa Webb and the V1 Internal Verifier award went to Lisa Webb and Claire Moscrop. 


\section{Nurse scoops top dental prize}

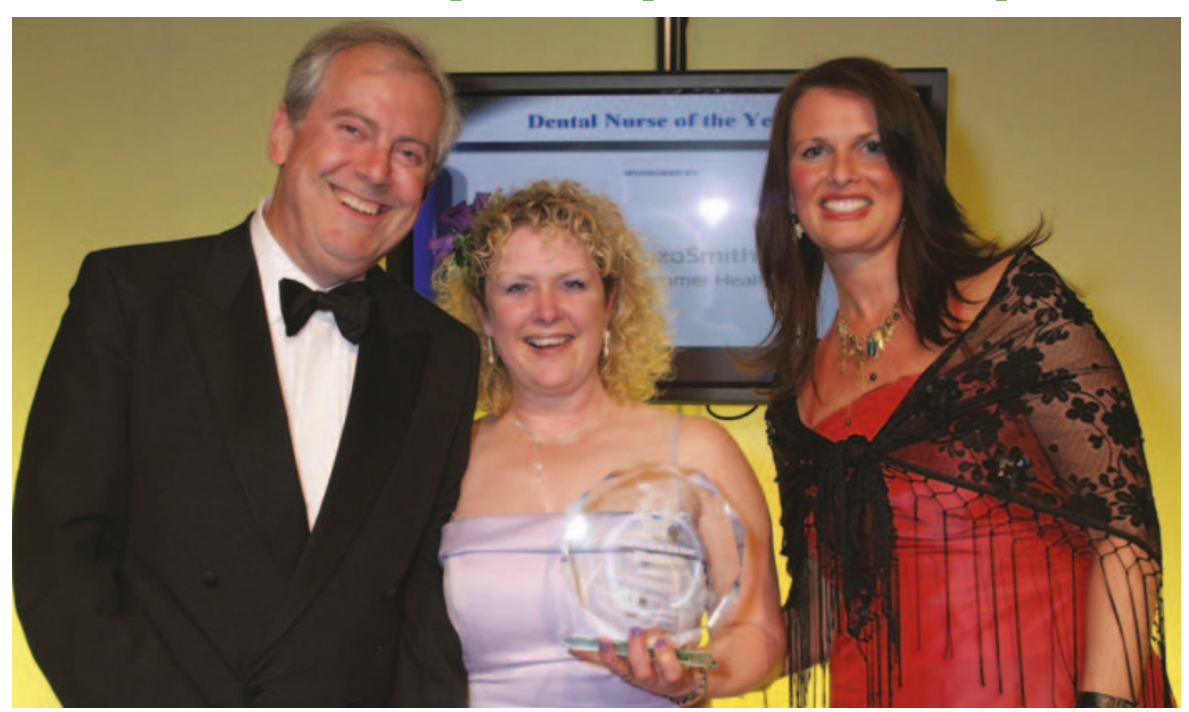

Pictured left to right, Compere Gyles Brandreth, with Dental Nurse of the Year Tina King and Vicky Hampson, Healthcare Professional Relations Director at GlaxoSmithKline.

A dental nurse from Devon has been named Dental Nurse of the Year at the Dental Awards 2005, held in April in London.

Tina King, from The Anchor Dental Centre, Devon won the prestigious award at the annual event, organised by The Probe and the British Dental Health Foundation.

Practice Manager of the Year went to Jane Armitage from the Thompson \& Thomas dental practice in Sheffield.
Stephen Osgathorpe of Dencraft, Sheffield was Dental Technician of the Year and the award for Dental Receptionist of the Year was presented to Rebecca Kipling of Springs Dental Practice in County Durham.

Dental Laboratory of the Year was awarded to PDS Dental Laboratory, Leeds and the Hygienist of the Year award went to Christine Cook of The Orthodontic Centre in Cardiff.

\section{Council proposes PCD fee}

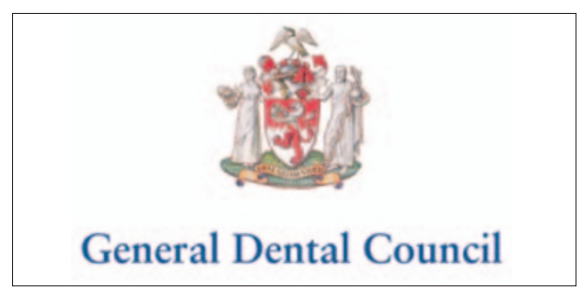

Professionals Complementary to Dentistry (PCDs) are likely to pay a $£ 68$ registration fee when the PCD Register opens in 2006, according to the General Dental Council (GDC).

The GDC said the fee was an indication of the amount that PCDs should pay for initial registration and that it should be the same as the annual retention fee for dental hygienists and therapists.

The final decision on the fees cannot be made until the legislation introducing PCD registration is in place, it said.

When the new PCD Register opens there will be a two-year transition period after which all PCDs will need to be registered with the GDC or be on a recognised training course.

To encourage PCDs to register sooner rather than later, the initial registration fee will cover the two-year transition period and the first year of compulsory registration.

The Council hopes that this 'three for the price of one' offer will encourage more PCDs to register early.

The annual fees that PCDs will need to pay to remain on the register after this period will be agreed at a future GDC meeting.

Changes in the law are needed before the GDC can start registering the new groups of PCDs.

The new legislation, which has been subject to Government delay, is expected to be in place in the summer and the GDC expects to open the register within 12 months of this.

For more information on PCD registration visit www.gdc-uk.org
Fluoride information centre launched

England's first fluoride information centre, based at Manchester University, has been launched to meet anticipated public demand for information following changes to the government's Water Bill.

The National Fluoride Information Centre (NFIC), set up with Department of Health Funding, will offer advice on fluoridation following a recent move that could mean that fluoride is added to water supplies in schemes across the country.

NFIC director Professor Anthony Blinkhorn said "we are the only information centre in England providing objective information on fluorides. As the national focal point for disseminating scientifically accurate information on fluorides, we offer unbiased information based on scientific literature".

The organisation's website (www. fluorideinformation.com) will be a onestop-shop for people wanting to find out more about fluoridation and will be updated as new information and research is published. The centre will also run a telephone helpline.

To find out more about changes to the Water Bill visit www.dh.gov.uk

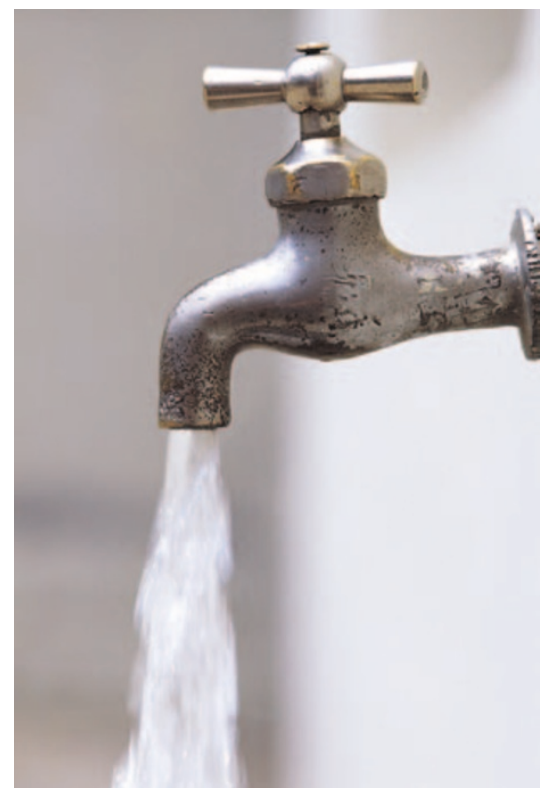

